\title{
Correction to: Dentate granule progenitor cell properties are rapidly altered soon after birth
}

\author{
Kenta Matsue $^{1} \cdot$ Shiori Minakawa $^{1} \cdot$ Taichi Kashiwagi $^{1} \cdot$ Keiko Toda $^{1} \cdot$ Toru Sato $^{1} \cdot$ Seiji Shioda $^{2} \cdot$ Tatsunori Seki $^{1}$
}

Published online: 25 January 2018

๑) Springer-Verlag GmbH Germany, part of Springer Nature 2018

Correction to: Brain Struct Funct (2018) 223:357-369

https://doi.org/10.1007/s00429-017-1499-7

In the original publication figure parts $8 \mathrm{c}, 8 \mathrm{f}$, and $8 \mathrm{i}$ were mixed up and thus incorrectly labeled. Here is a corrected version with the parts properly labeled:
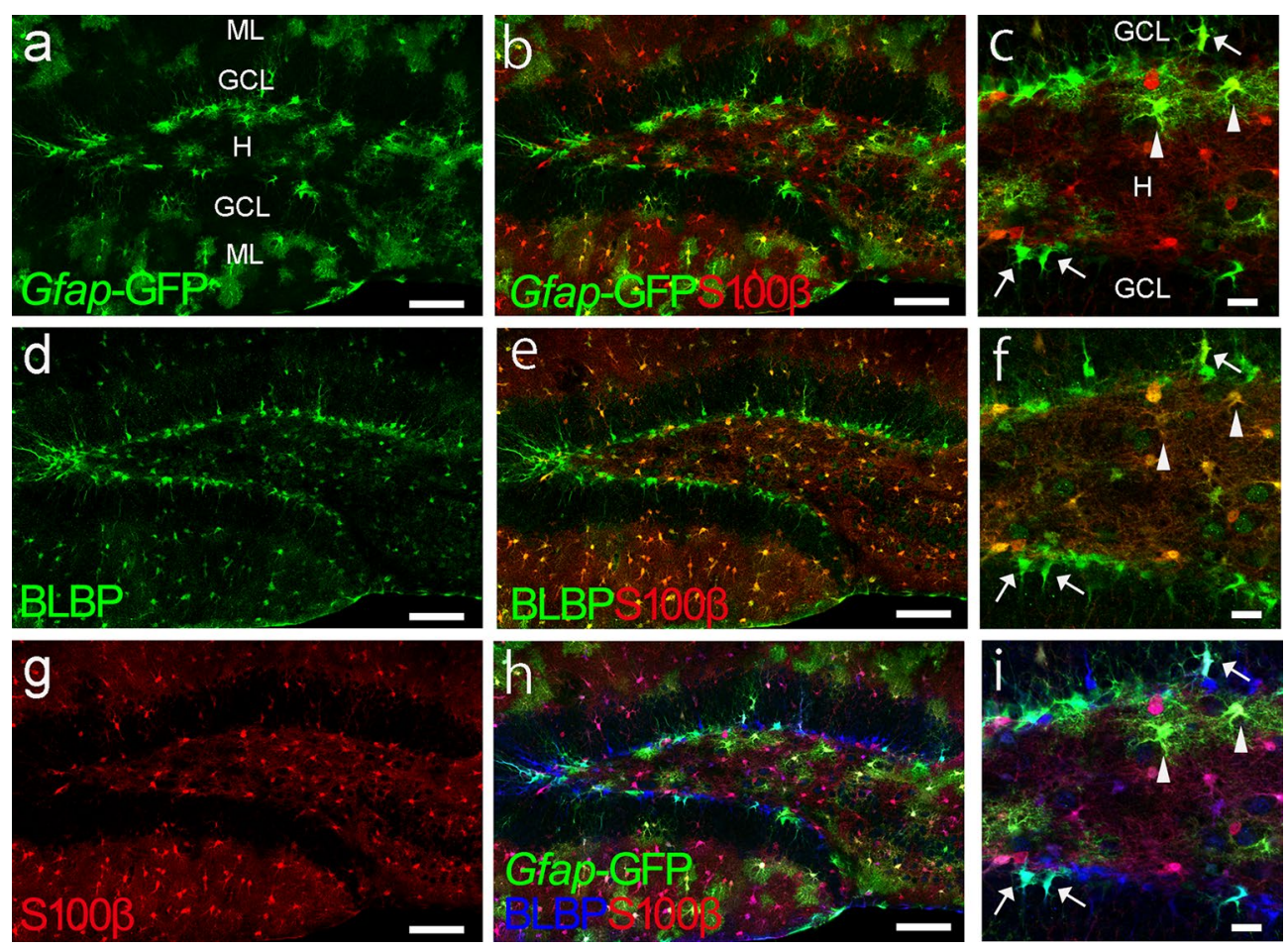

The original article can be found online at https://doi.org/10.1007/ s00429-017-1499-7.

Tatsunori Seki

sekit@tokyo-med.ac.jp

1 Department of Histology and Neuroanatomy, Tokyo

MedicalUniversity, 6-1-1 Shinjuku, Shinjuku-ku,

Tokyo 160-8402, Japan

2 Institute for Advanced Bioscience Research, Hoshi

University, Tokyo, Japan 